\title{
An investigation of the influence of selected factors on the properties of spruce wood
}

\section{Journal Article}

Author(s):

Sonderegger, Walter; Mandallaz, Daniel; Niemz, Peter

Publication date:

2008

Permanent link:

https://doi.org/10.3929/ethz-b-000010887

Rights / license:

In Copyright - Non-Commercial Use Permitted

Originally published in:

Wood Science and Technology 42(4), https://doi.org/10.1007/s00226-007-0173-2 


\title{
An investigation of the influence of selected factors on the properties of spruce wood
}

\author{
Walter Sonderegger $\cdot$ Daniel Mandallaz $\cdot$ Peter Niemz
}

Received: 23 April 2007/Published online: 18 December 2007

(C) Springer-Verlag 2007

\begin{abstract}
Thirty Norway spruce trees (Picea abies (L.) Karst.) from the forest district of the ETH Zurich were tested for bending MOR, static MOE of bending and dynamic MOE (calculated from eigenfrequency and sound velocity). The specimens were clear and were sampled from the whole of the stem. Their correlations to density, annual ring width, height in the tree, distribution over the stem diameter and the percentage of compression wood were statistically analysed. All three elasticity modules and the maximal stress can be very well predicted from a linear function of the sample density with a common gradient across the compression wood values but with different intercepts that decrease with increasing compression wood content. The other variables have highly significant impacts on the response variables too, however, this is largely irrelevant for the goodness of fit. Further, a clear increase of density, of MOE and of bending MOR was measured from pith to bark and similarly with decreasing annual ring width. Concerning the height of the stem, no distinct trend for the mechanical properties could be found.
\end{abstract}

\section{Introduction and state of knowledge}

Within the scope of this paper, clear bending specimens of Norway spruce wood distributed over the whole stem were investigated on several physical, anatomical and mechanical properties and statistically analysed.

\footnotetext{
W. Sonderegger $(\bowtie) \cdot$ P. Niemz

Department of Civil, Environmental and Geomatic Engineering, Institute for Building Materials, ETH Zurich, 8093 Zurich, Switzerland

e-mail: wsonderegger@ethz.ch

D. Mandallaz

Department of Environmental Sciences, Institute of Terrestrial Ecosystems, ETH Zurich, 8092 Zurich, Switzerland
} 
The properties of wood vary largely within a species, both within a tree and among trees. Zobel and Van Buijtenen (1989) give a comprehensive review of the abundant literature available in this context. Mette (1984), Knigge and Schulz (1966) and Walker (2006) provide an overview of the essential differences of properties between wood species. Trendelenburg (1937) has already analysed the distribution of density and compression strength over the stem in a diverse range of conifers (larch, pine, spruce). Spruce wood had the smallest change in density within a stem and pinewood had the highest. For spruce wood, the differences between one stem to another are higher than within a stem. For pinewood, the relationship between strength and density varies remarkably (about 15\% higher in the middle than in the bottom part) caused by the higher resin content in the bottom part of the stem. Kollmann (1951) and Volkert (1941) investigated the relationship between annual ring width and density. Thereby, they found that the density increased with decreasing annual ring width in spruce but a culmination (highest density) was found in larch and pine (results were not so distinct for Douglas fir and fir) in the range of 1-2 $\mathrm{mm}$ of annual ring width. Vorreiter (1937) tested in detail the compression and bending strength of spruce wood from various altitudes and depending on the position within a stem. Thereby, the strengths increased with increasing density, late wood content and distance from the pith and with decreasing altitude, annual ring width and height in the stem (cf. also Vorreiter 1954). Kollmann (1978) provides an overview of multiple wood species over the distribution of the density within a stem and within a species.

Recently, investigations evaluating the quality of large diameter round wood of spruce were made (e.g. Reiter 2005; Glos and Pahler 2006; Teischinger and Müller 2006). Thereby, the increase of the density and the decrease of the knot area ratio with increasing distance from the pith were analysed. Both characteristics strongly influence the wood quality. Moreover, the influence of the position within the stem for bending and tensile strength was analysed, though not on clear specimens but on boards or beams including knots and other wood defects.

Similar investigations into swelling, warping, bending strength and stiffness of fast-grown Norway spruce logs depending on the position in the stem were carried out by Perstorper et al. (1995a, 1995b) and Kliger et al. (1995). The variation of wood properties from both a fast-grown and a slow-grown stand was analysed by Perstorper et al. (2001). Thereby, a clear influence of juvenile wood and compression wood was stated.

For maritime pinewood, Machado and Cruz (2005) analysed variations of bending strength and stiffness, compression strength parallel to grain and tensile strength perpendicular to grain depending on the position within the stem.

\section{Materials and methods}

The testing material was taken from 30 trees (breast-height diameter about 40$80 \mathrm{~cm}$ ) of approx. 120-year-old Norway spruce wood (Picea abies (L.) Karst.). The trees were used for diverse investigations into the wood quality affected by 
the storm Lothar, in December 1999 (cf. Arnold 2004; Sonderegger and Niemz 2004). The wood came from the forest district of the ETH Zurich, about $5 \mathrm{~km}$ to the west of the city of Zurich at 705-715 m above sea level on the west slope of the mountain 'Üetliberg'. The timber stand was grown on intermediate brown soil and had a grade of mixture of $50 \%$ spruce, $40 \%$ fir and $10 \%$ beech, maple and ash. The mean annual precipitation is $1,150 \mathrm{~mm}$ and the mean annual temperature is $6-8^{\circ} \mathrm{C}$.

Altogether, 991 specimens for bending were taken from the trees for testing the influence of the diverse parameters of structure within a stem on the strength and the modulus of elasticity. For the production of the specimens, all of the trees were cut into three to five stem sections of $5 \mathrm{~m}$ (total 128 sections). From the lower $2 \mathrm{~m}$ of each stem section, a $10 \mathrm{~cm}$ thick centre board was cut in the orientation of the main wind direction (west wind) and within this board a $50 \mathrm{~cm}$ long section without knots was chosen and cut into $35 \mathrm{~mm}$ thick slats whereof one to nine clear specimens for bending (proportions: $20 \mathrm{~mm} \times 20 \mathrm{~mm} \times 400 \mathrm{~mm}$ ) according to DIN 52186 were prepared from each side of the centre board (Fig. 1).

The specimens were stored in normal climate $\left(20^{\circ} \mathrm{C} / 65 \% \mathrm{RH}\right)$ until constant weight and thereafter, the following properties were determined and tested against:

- height in the tree

- distance from the bark

- annual ring width

- compression wood

Fig. 1 Opening cut of the specimens for bending from the centre boards

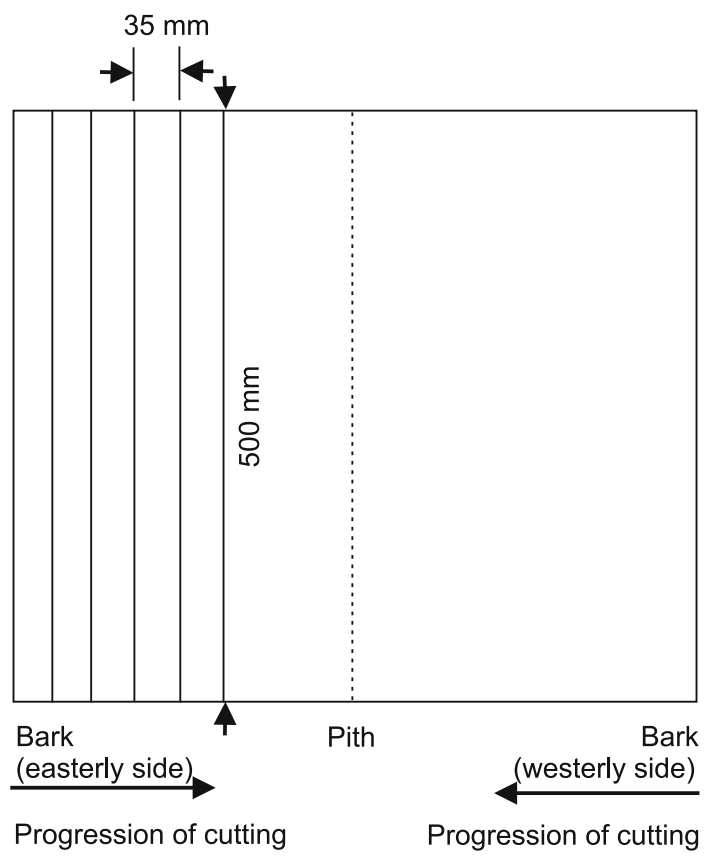


- density

- bending strength and MOE according to DIN 52186

- eigenfrequency (vibration of first order using the tester GrindoSonic Mk5 'Industrial' of the company J.W. Lemmens, Belgium)

- sound velocity (parallel to the grain using ultrasonic tester BP5 of the company Steinkamp, Bremen (Germany) with a frequency of $50 \mathrm{kHz}$ )

From the measured eigenfrequencies and sound velocities, the dynamic MOE was calculated according to the following formulas.

The MOE calculated from eigenfrequency was calculated according to Eq. 1 (Görlacher 1984) without consideration of the influence of shear modulus:

$$
E=\frac{4 \times \pi^{2} \times l^{4} \times f^{2} \times \rho}{m_{\mathrm{n}}^{4} \times i^{2}} \times\left(1+\frac{i^{2}}{l^{2}} \times K_{1}\right) .
$$

where

$\begin{array}{ll}E & \text { modulus of elasticity }\left(\mathrm{N} / \mathrm{mm}^{2}\right) \\ l & \begin{array}{l}\text { length of the specimen }(\mathrm{mm}) \\ \text { eigenfrequency }\left(\mathrm{s}^{-1}\right)\end{array} \\ \rho & \begin{array}{l}\text { density }\left(\mathrm{kg} / \mathrm{m}^{3}\right) \\ \text { gyration radius in direction of the bending vibration } \\ i\end{array} \\ K_{1} \text { and } m_{\mathrm{n}}^{4} & \begin{array}{l}\text { constants depending on the order of vibration } \\ \left.\text { (for vibrations of first order: } K_{1}=49.48 ; m_{\mathrm{n}}^{4}=500.6\right)\end{array}\end{array}$

The MOE calculated from sound velocity was calculated according to Eq. 2 (Niemz 1993):

$$
E=c^{2} \times \rho .
$$

where

$$
\begin{array}{ll}
E & \text { modulus of elasticity }\left(\mathrm{N} / \mathrm{mm}^{2}\right) \\
c & \text { sound velocity }(\mathrm{m} / \mathrm{s}) \\
\rho & \text { density }\left(\mathrm{kg} / \mathrm{m}^{3}\right)
\end{array}
$$

Thereafter, the experimentally determined properties of the specimens were statistically analysed.

The statistical analyses were performed with the software S-PLUS and SAS. For the figures, the following abbreviations are used.

For the response variables:

E1 static MOE, determined by mechanical testing on the sample (DIN 52186) $\left(\mathrm{N} / \mathrm{mm}^{2}\right)$

E2 MOE calculated on the basis of the measured eigenfrequency of the sample $\left(\mathrm{N} / \mathrm{mm}^{2}\right)$

E3 MOE calculated on the basis of the sound velocity in the sample $\left(\mathrm{N} / \mathrm{mm}^{2}\right)$ MOR bending strength (DIN 52186) $\left(\mathrm{N} / \mathrm{mm}^{2}\right)$ 
For the explanatory variables:

$c$ sound velocity $(\mathrm{m} / \mathrm{s})$

$f \quad$ eigenfrequency $\left(\mathrm{s}^{-1}\right)$

rw annual ring width ( $\mathrm{mm}$ )

$h$ height of the sample in the tree (m)

$d$ distance from the bark $(\mathrm{cm})$

$\rho$ density of the sample $\left(\mathrm{kg} / \mathrm{m}^{3}\right)$

$s \quad$ side of the sample, $s=1$ : easterly (downwind) side, $s=-1$ : westerly (windward) side

$\mathrm{cw}$ proportion of compression wood (\%)

\section{Results}

General relationships between the variables

In the first step, the relationships between the response variables and between the explanatory variables were analysed. All variables were determined on the same wood sample. For this preliminary analysis all the 991 observations were used. Tables 1 and 2 illustrate the correlation matrix between the response variables (E1, E2, E3, MOR) and between the structurally determined, explanatory variables $(d, h, \mathrm{rw}, \rho)$.

All correlations between the response variables (both, between the different tested MOE and between the MOE and bending strength) are very high. The MOE calculated from eigenfrequency (E2) provides an excellent linear predictor of the static MOE (E1) with a very high correlation of 0.988 . The MOE calculated from sound velocity (E3) is a good predictor of E1, but obviously not as good as E2 and all MOE are good predictors of the bending strength (MOR).

The differences between the two dynamic MOE values are due to the respective measurement methods. For the determination of sound velocity in contrast to the eigenfrequency, on the one hand the longitudinal wave propagation (eigenfrequency:

Table 1 Correlation matrix between the response variables

\begin{tabular}{llll}
\hline & E2 & E3 & MOR \\
\hline E1 (MOE) & 0.99 & 0.95 & 0.91 \\
E2 (MOE) & - & 0.96 & 0.91 \\
E3 (MOE) & - & - & 0.90 \\
\hline
\end{tabular}

\begin{tabular}{llcl}
\hline & $h$ & rw & $\rho$ \\
\hline$d$ (distance) & -0.17 & 0.72 & -0.51 \\
$h$ (height) & - & -0.014 & -0.04 \\
rw (annual ring width) & - & - & -0.60 \\
\hline
\end{tabular}

Table 2 Correlation matrix between the explanatory variables 
bending vibration) and on the other hand the fastest incoming wave (eigenfrequency: medium vibration of first order) was measured.

The correlations between the explanatory variables are not very high. A distinct correlation exists only for three of the six dependencies: between the distance from the bark $(d)$ and the annual ring width (rw), between the density $(\rho)$ and the annual ring width, and between the density and the distance from the bark $(d)$. The correlation between the distance from the bark and the annual ring width depends on the fact that the annual ring width decreases with increasing age of the tree. The correlation between the annual ring width and the density depends on the anatomical behaviour of some conifers, such as spruce, where the volume of latewood does not change with different ring width and so the density increases with decreasing ring width. The correlation between the distance from the bark and the density is a result of the lower density of the juvenile wood but also of the decreasing annual ring width from pith to bark.

Figures 2 and 3 show the linear regressions between the static MOE (E1) and the two dynamic MOE calculated from the non-destructive testing methods: eigenfrequency (E2) and sound velocity (E3). There is a poorer correlation between the bending MOR and the static MOE with a coefficient of determination of $75 \%$ (Fig. 4).

Figures 5 and 6 show the correlation between the static MOE (E1) and the variables of non-destructive testing: eigenfrequency and sound velocity. The quadratic relationship is of course due to the formulae of Görlacher (Eq. 1) in the case of eigenfrequency and of Eq. 2 in the case of sound velocity. The large variance about the fitted curve is mainly due to the density $\rho$ in the formulae.

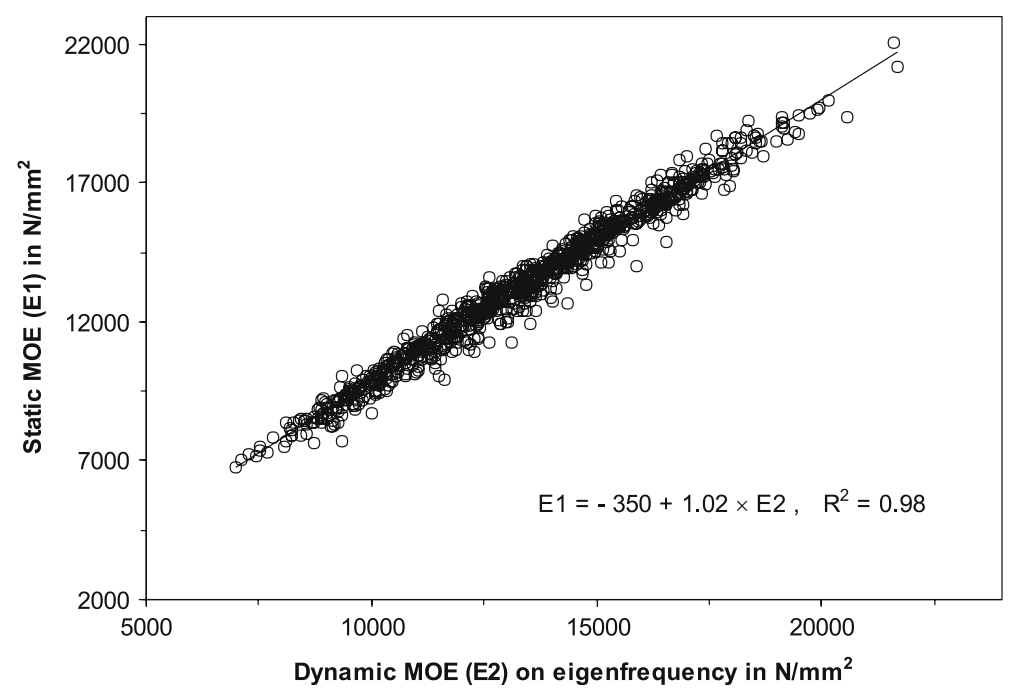

Fig. 2 Linear regression between the static MOE (E1) and the dynamic MOE calculated from eigenfrequency (E2), all 991 observations 


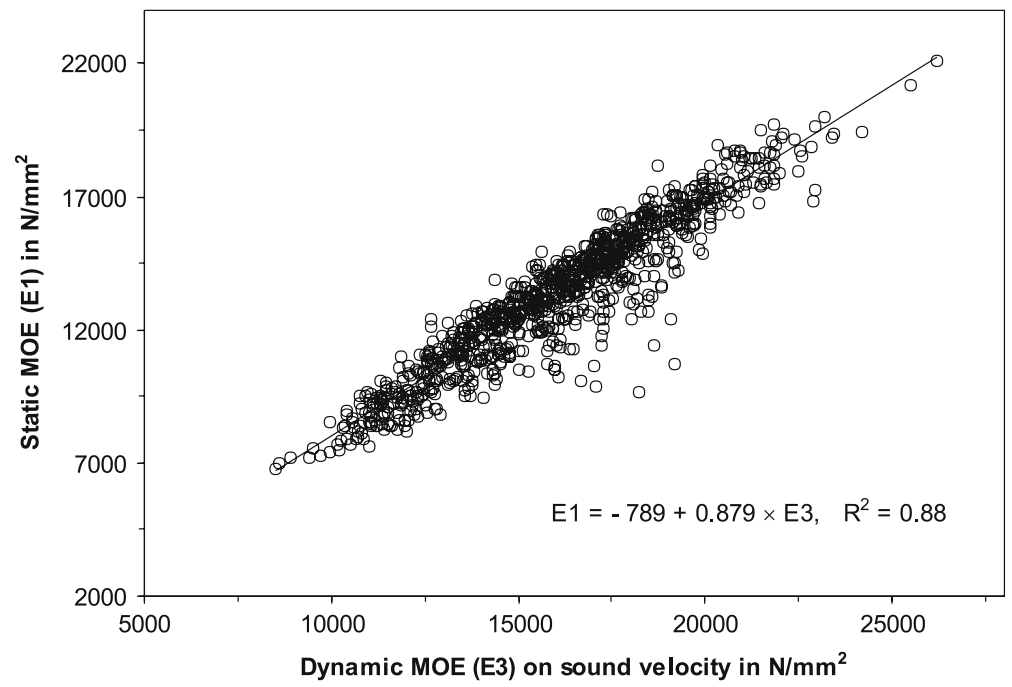

Fig. 3 Linear regression between the static MOE (E1) and the dynamic MOE calculated from sound velocity (E3), all 991 observations

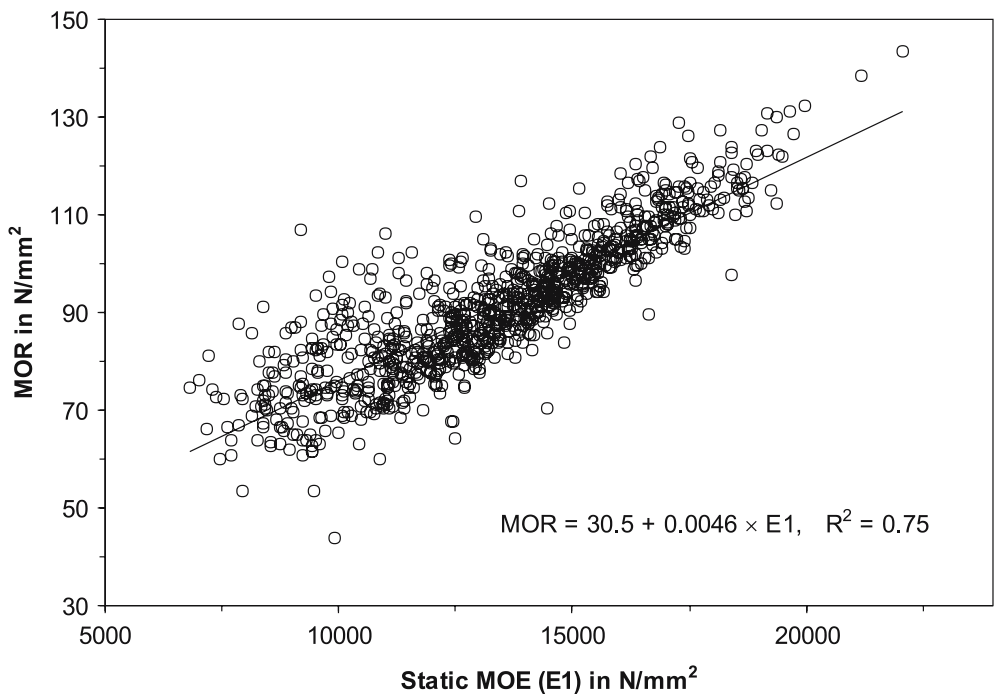

Fig. 4 Linear regression between MOR of bending and static MOE (E1), all 991 observations

Influence of the sample position on the density

Density clearly increases from pith to bark (Fig. 7). This is in agreement with the correlation between annual ring width and density, where it was found that the density of spruce wood within the site decreased with increasing annual ring. No explicit trend is shown concerning the height of the specimen within the stem. The 


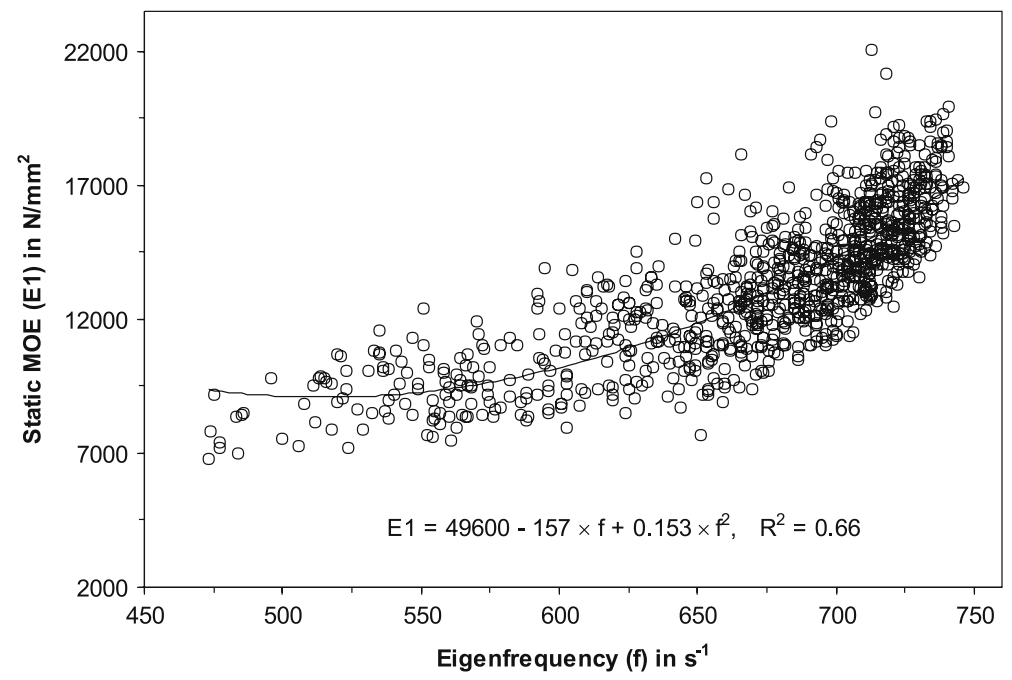

Fig. 5 Quadratic regression between static MOE (E1) and eigenfrequency ( $f$ ), all 991 observations

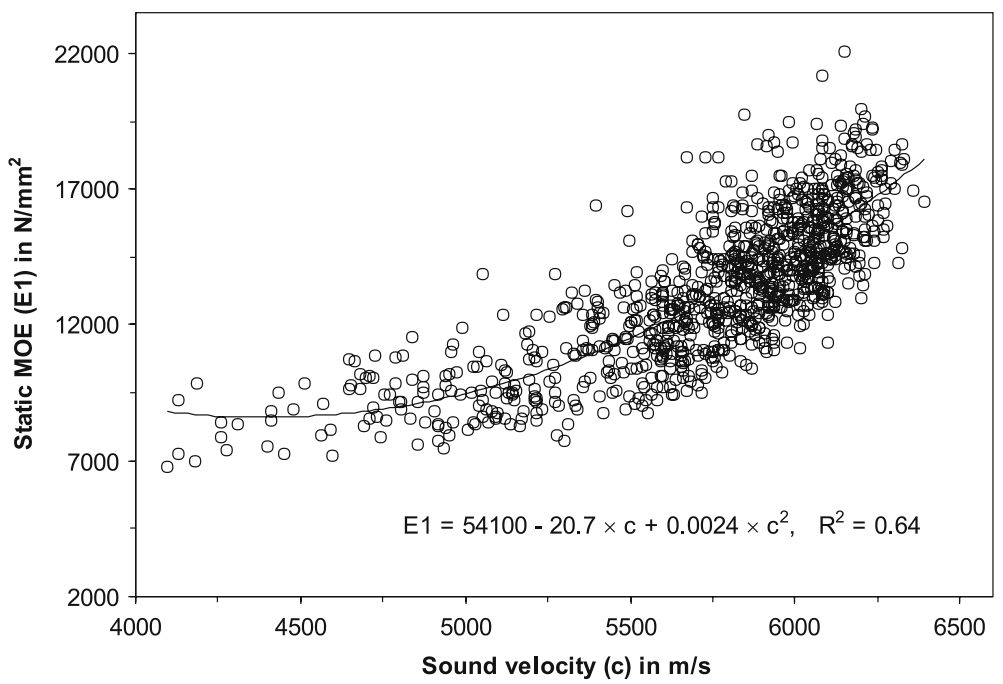

Fig. 6 Quadratic regression between static MOE (E1) and sound velocity (c), all 991 observations density changes just marginally with increasing height within the stem, but the distribution of the values obviously increases with increasing height.

Influence of the annual ring width, the distance pith-bark and the height of the sample in the tree on the mechanical properties

Density linearly correlates with wood strength and modulus of elasticity. So the tendencies for density can be observed for MOE in correlation with the variables 


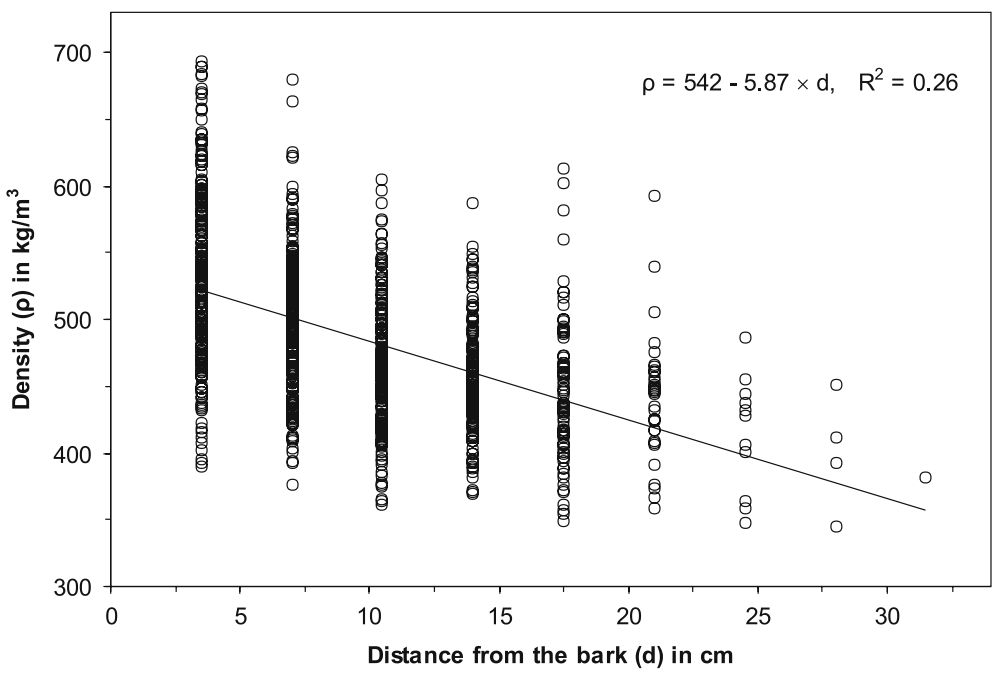

Fig. 7 Correlation between density $(\rho)$ and distance from the bark $(d)$, all 991 observations

within the tree (Figs. 8, 9, 10). Because the annual ring width decreases from pith to bark, the MOE increases toward the bark, since annual ring width and the distance from the bark correlate together. For MOE and MOR, it should be noted, that in addition to the influence of density, also the fibre length and the microfibril angle increase from pith to bark and the microfibril angle decreases with increasing height of the stem (cf. Teischinger and Müller 2006). However, microfibril angle and fibre length, in addition to the density, have a great influence on the MOE and MOR of the wood. MOE and MOR increase with increasing fibre length and decreasing microfibril angle. Thus, complex interactions exist. Microfibril angle and fibre length were not determined in this paper because this would have increased the volume of the tests substantially. Nonetheless, the influence of these properties should be determined. Correspondent investigations were made for Pinus radiata trees. Walker (2006) provides a comprehensive overview of this.

The MOE slightly declines with increasing height of the stem (Fig. 10). Grouping of the values within a distance of about $5 \mathrm{~m}$ is due to the sampling method. The distribution of the values increases with increasing height of the sample within the stem. The reason for the slight decrease of the MOE with increasing height of the stem - in contrast to the density - is due to the slight increase of compression wood with increasing height of the stem.

Influence of density and compression wood on the mechanical properties

The tested wood had a remarkably strong section of compression wood due to the forest site (wind exposed). The percentage of compression wood, measured on the cross section, was also determined by classifying the sample into specimens with and without graded parts of compression wood. Table 3 gives an overview of the 


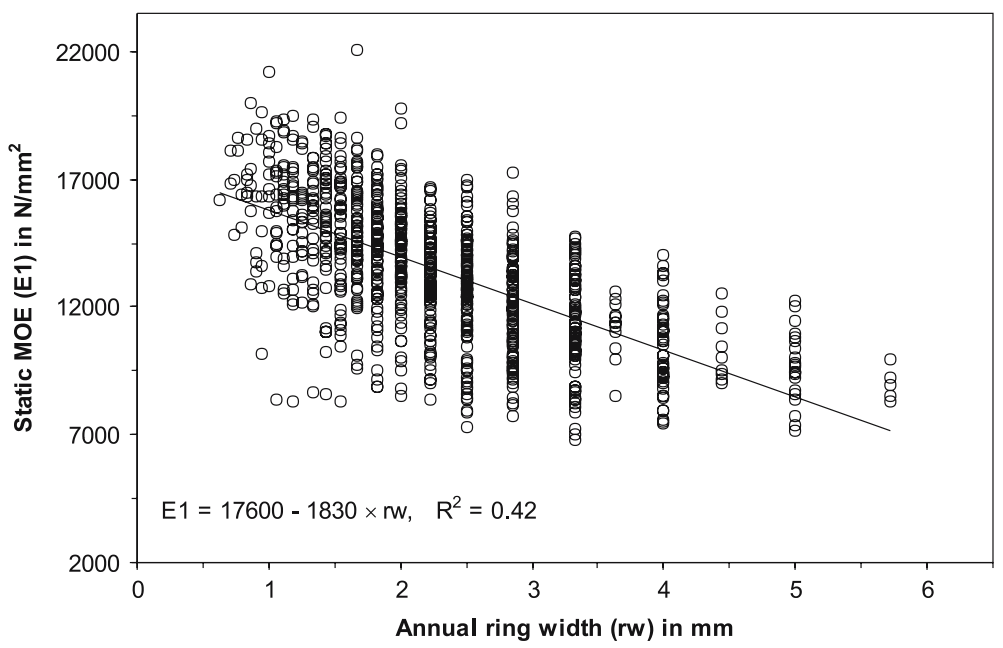

Fig. 8 Static MOE (E1) depending on annual ring width (rw), all 991 observations

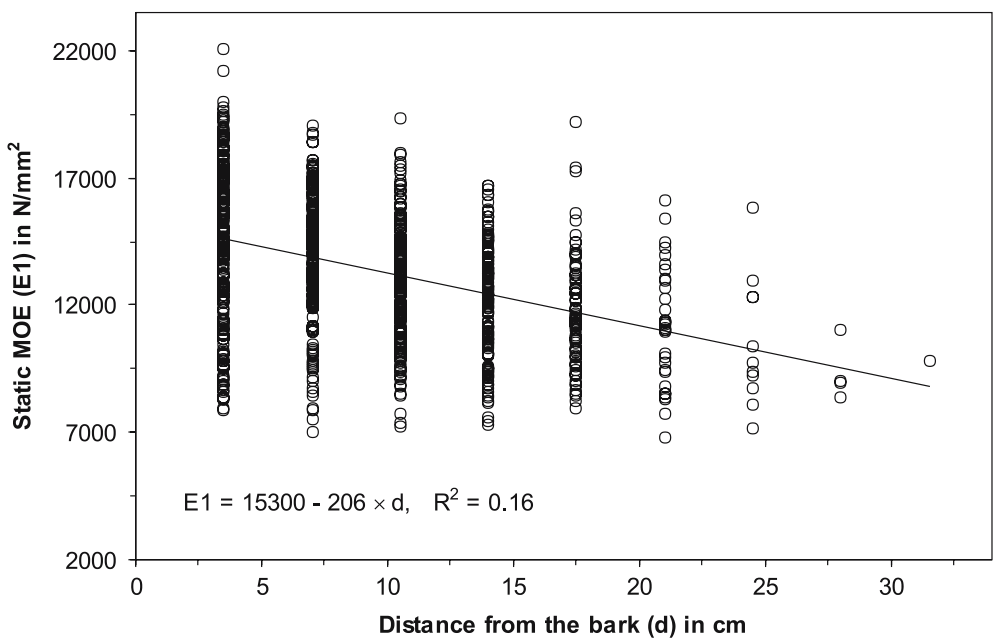

Fig. 9 Static MOE (E1) depending on the distance from the bark (d), all 991 observations

number of specimens per part of compression wood and the corresponding densities, bending strengths and modulus of elasticity.

Thereby the range of the specimens varies highly. It appears that the density clearly increases with increasing percentage of compression wood. There is no apparent trend for the bending MOR, but the static MOE clearly decreases.

This agrees with measurements of compression wood in Timell (1986) and is caused by the fact that compression wood has greater lignin content as normal wood and a higher microfibril angle in the S2-layer of the cell wall. So the influence of the higher density is countervailed through these factors (bending MOR) or more than countervailed (MOE). 


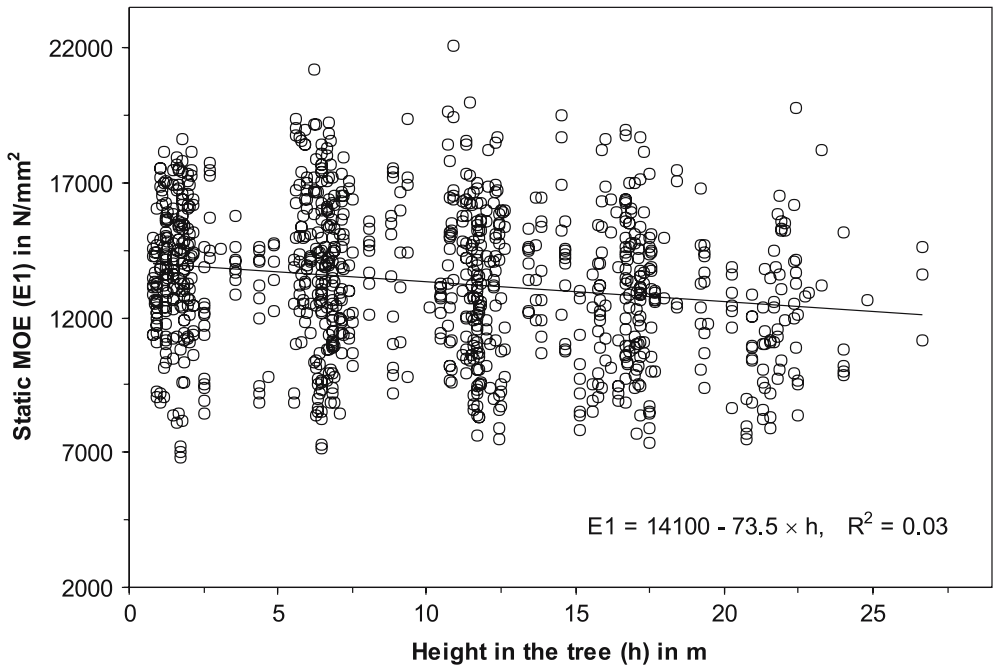

Fig. 10 Static MOE (E1) depending on the height of the sample in the tree $(h)$, all 991 observations

Table 3 Mean values of density, bending strength (MOR) and MOE classified by percentage of compression wood (cw)

\begin{tabular}{lllll}
\hline $\begin{array}{l}\text { Compression } \\
\text { wood }(\mathrm{cw})(\%)\end{array}$ & $\begin{array}{l}\text { Number of } \\
\text { samples }\end{array}$ & $\begin{array}{l}\text { Density } \\
\left(\mathrm{kg} / \mathrm{m}^{3}\right)\end{array}$ & $\begin{array}{l}\text { Bending MOR } \\
\left(\mathrm{N} / \mathrm{mm}^{2}\right)\end{array}$ & $\begin{array}{l}\text { Static MOE } \\
\left(\mathrm{N} / \mathrm{mm}^{2}\right)\end{array}$ \\
\hline 0 & 599 & 469 & 92.9 & 14,200 \\
5 & 76 & 479 & 90.0 & 13,300 \\
10 & 93 & 488 & 88.8 & 12,900 \\
20 & 82 & 496 & 86.4 & 11,800 \\
30 & 62 & 525 & 90.3 & 11,600 \\
40 & 27 & 561 & 91.0 & 11,200 \\
50 & 23 & 567 & 90.6 & 10,600 \\
60 & 19 & 587 & 87.1 & 9,480 \\
70 & 10 & 596 & 95.3 & 10,100 \\
\hline
\end{tabular}

Walker (2006) gives an overview of the influence of compression wood. He summarised the following property changes:

- increase of the density

- reduction of the fibre length of about $10-25 \%$

- more longitudinal shrinkage of $0.1-0.35 \%$ for normal wood to $3-5 \%$ for compression wood

- clear reduction of MOE

- no distinct change of the MOR (increase of the MOR caused by higher density, reduction of the MOR caused by increasing microfibril angle and decreasing fibre length) 
The regression analysis of the static MOE over all specimens, in correlation with the density, shows a clear influence of the specimens containing compression wood. The rating of the regression clearly declines when specimens of compression wood are included. The coefficient of determination is only $20 \%$ using all specimens in one main unit. For comparison, regression lines from the influence of density for different percentages of compression wood (cw) were calculated in Fig. 11. Due to the small number of observations available in the categories $\mathrm{cw}=40,50,60,70$ the analysis was restricted to 912 of the 991 observations with $\mathrm{cw}=0,5,10,20,30$. The significantly higher correlation is clearly visible (see below). Similarly, Fig. 12 shows the regression lines of the bending MOR in correlation with the density for various proportions of compression wood.

Relationships between the variables on the basis of multiple regression models

As shown by the previous figures, the impact of the explanatory variables on the response variables is clear. Due to the very large data set, one can fit rather complex models with quadratic trends for every explanatory variable. However, the significant quadratic terms reflect more the large sample size and the fact that there are always deviations from the strict linearity rather than physically meaningful relations. Indeed, quadratic terms imply the existence of maxima or minima, which are certainly artefacts in the present context. This is also confirmed by the coefficient of determination $R^{2}$ (the percentage of the variance explained by the model), which is, e.g. 0.87 for a full quadratic model as compared to 0.85 with a

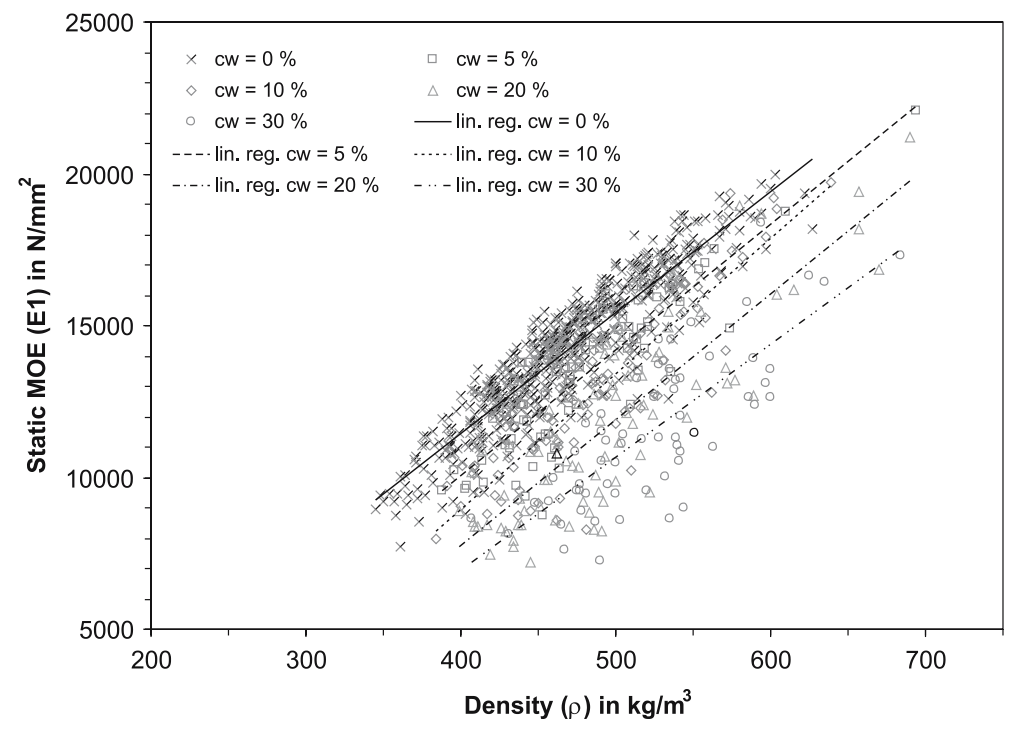

Fig. 11 Static MOE (E1) depending on density ( $\rho$ ), classified by percentage of compression wood (cw), 912 observations 


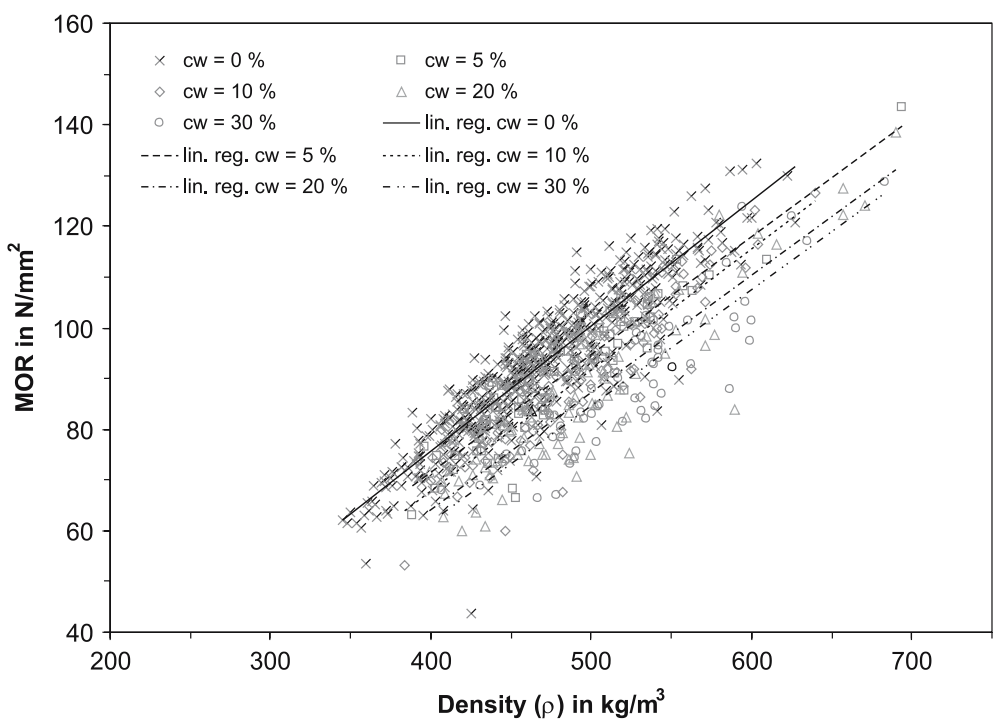

Fig. 12 Bending strength (MOR) depending on density $(\rho)$, classified by percentage of compression wood $(\mathrm{cw}), 912$ observations

full linear model. The difference is really not worth the increased complexity. For these reasons, results with linear trends with only respect to the explanatory variables are presented. Furthermore, because of the large sample size, the residuals from the multiple regressions depart significantly from the normal distribution, though they looked "bell-shaped". That is why, a robust regression (Huber-method in SPLUS) was also performed. Since the robust estimates of the regression coefficients were never significantly different from the standard least squares estimates only the later ones are presented, as they are more familiar to the majority of readers. Also, the robust estimates can vary slightly from one software-user to another because of the choice of "tuning constants", whereas the least squares estimates are "universal". Stratified analysis according to the east side and the west side of the trees did not reveal differing trends of these variables.

Therefore, a full and a simple linear model for the static MOE and the MOR of bending will be presented below. Just as in Figs. 11 and 12, the analysis is restricted to the 912 of 991 observations with a portion of compression wood (cw) of $0,5,10$, 20 and $30 \%$.

\section{Full linear model for the static MOE (E1)}

Table 4 shows the regression for all parameters. The coefficient of determination for the full linear model is $R^{2}=0.83$.

The equations for the different percentage of compression wood read for E1 by the full linear model result from the estimated values of the parameters in Table 4. This means for $\mathrm{cw}=0$ : 
Table 4 Values for the multiple regression for all tested parameters for static MOE (E1)
The reference value for the categorical variable $\mathrm{cw}$ is $\mathrm{cw}=30($ SAS coding $)$

\begin{tabular}{llll}
\hline Parameter & Estimate & Standard error & $t$ Value \\
\hline Intercept & $-7,900$ & 640 & -12.3 \\
$s$ & -353 & 48.3 & -7.31 \\
$\mathrm{cw} 0$ & 4,230 & 168 & 25.2 \\
$\mathrm{cw} 5$ & 3,400 & 193 & 17.6 \\
$\mathrm{cw} 10$ & 2,680 & 183 & 14.7 \\
$\mathrm{cw} 20$ & 1,350 & 185 & 7.30 \\
$\mathrm{cw} 30$ & 0.00 & - & - \\
$h$ & -15.0 & 5.99 & -2.50 \\
$d$ & 61.7 & 10.6 & 5.80 \\
rw & -395 & 62.8 & -6.30 \\
$\rho$ & 38.8 & 0.97 & 39.9 \\
\hline
\end{tabular}

$$
\mathrm{E} 1_{d h 0}=-3,670-353 \times s-15 \times h+61.7 \times d-395 \times \mathrm{rw}+38.8 \times \rho .
$$

For the other equations, only the first value differs and could be calculated from the addition of the intercept and the estimated value of $\mathrm{cw}$. Thus the first values are $-4,500$ for $\mathrm{cw} 5 ;-5,220$ for $\mathrm{cw} 10 ;-6,550$ for $\mathrm{cw} 20$ and $-7,900$ for $\mathrm{cw} 30$.

All explanatory variables are significant:

- the westerly side of the tree $(s=-1)$ yield significant higher E1-values than the easterly side $(s=1)$

- the E1-values decrease with increasing compression wood (cw)

- the E1-values decrease with increasing ring width (rw)

- the E1-values decrease slightly with increasing height in the tree $(h)$

- the E1-values increase with increasing density $(\rho)$

These findings are in agreement with the considerations made above (cf. Figs. 8, 9, 10). This is not the case for the distance $(d)$ where the full model implies an increase of the E1-values with increasing distance (while keeping the other explanatory variables constant). This is due to the correlation between the explanatory variables shown in Table 2.

\section{Simple linear model for the static $M O E(E 1)$}

To facilitate the interpretation, a very simple linear model was considered in which the static MOE is a linear function of the density $\rho$ (common slope) and varying intercept according to the compression wood (cw) value (Table 5).

The equations for the different percentage of compression wood read for E1 by the simple linear model are strongly reduced compared to Eq. 3. Equation 4 applies for $\mathrm{cw}=0$ :

$$
\mathrm{E} 1_{d h 0}=-4,800+40.5 \times \rho .
$$


Table 5 Parameters for the regression density $(\rho)-$ static MOE (E1) for different proportions of compression wood (cw)

\begin{tabular}{llll}
\hline Parameter & Estimate & Standard error & $t$ Value \\
\hline cw 0 & $-4,800$ & 340 & -14.1 \\
cw 5 & $-6,060$ & 369 & -16.4 \\
cw 10 & $-6,890$ & 370 & -18.6 \\
cw 20 & $-8,300$ & 378 & -22.0 \\
cw 30 & $-9,660$ & 404 & -23.9 \\
$\rho$ & 40.5 & 0.717 & 56.4 \\
\hline
\end{tabular}

The remaining equations are calculated analogically with the estimated values of the respective cw and of $\rho$.

The $R^{2}$ decreases marginally from 0.83 for the full linear model to 0.81 for the above simplified model. The interaction term slope $\times \mathrm{cw}$ is not significant, which simply confirms the graphical impression and justifies the simple model.

For the practical purpose of predicting the E1-module, the linear regression on the sample density with common slope and intercept term depending on the $\mathrm{cw}$ value, gives essentially the same goodness of fit as the more complex models, which of course reveal some interesting aspects of the other variables involved. Finally, a stratified analysis according to $\mathrm{cw}$ reveals that the slope coefficient with respect to the density $(\rho)$ was remarkably constant around 40 .

Due to the high correlation and excellent linear relationship between E1 and the other explanatory variables, it is obvious that one can use the same simplified model for E2, E3 and MOR as a function of the density $(\rho)$ and the $\mathrm{cw}$ values. The results for the E2 module are practically the same as for the E1 module, as expected. The goodness of fit is even slightly better with $R^{2}=0.83$. The results for E3 with $R^{2}=0.81$ are very similar to those of E1, though the slope and intercept terms differ significantly due to the generally higher values of E3 compared with E1 and E2 (cf. linear regressions in Figs. 2 and 3).

The results for MOR are as follows.

\section{Full linear model for bending strength (MOR)}

The calculated parameters for the regression can be seen in Table 6 .

The equations for the different percentage of compression wood read for MOR by the full linear model are similar to Eq. 3. For example, Eq. 5 applies for $\mathrm{cw}=0$ :

$$
\operatorname{MOR}_{d h 0}=-13.9-2.51 \times s-0.21 \times h+0.24 \times d-1.59 \times \mathrm{rw}+0.23 \times \rho
$$

Again, all the explanatory variables have a significant impact on the MOR. The regression coefficients have the same signs and therefore same interpretation as for the E-modules (this is obvious as the correlation of MOR with E1, E2, E3 is very high, around 0.9). 
Table 6 Values for the multiple regression for all tested parameters for bending strength

The reference value for the categorical variable $\mathrm{cw}$ is $\mathrm{cw}=30($ SAS coding $)$

Table 7 Parameters for the regression density $(\rho)$ - bending strength (MOR) for different proportions of compression wood

\begin{tabular}{lclc}
\hline Parameter & Estimate & Standard error & $t$ Value \\
\hline Intercept & -25.4 & 3.31 & -7.67 \\
$s$ & -2.51 & 0.25 & -10.1 \\
cw 0 & 11.5 & 0.87 & 13.2 \\
cw 5 & 9.20 & 0.99 & 9.23 \\
cw 10 & 6.75 & 0.94 & 7.15 \\
cw 20 & 2.90 & 0.96 & 3.02 \\
cw 30 & 0.00 & - & - \\
$h$ & -0.21 & 0.031 & -6.72 \\
$d$ & 0.24 & 0.055 & 4.38 \\
rw & -1.59 & 0.325 & -4.91 \\
$\rho$ & 0.23 & 0.0050 & 46.3 \\
\hline
\end{tabular}

\begin{tabular}{lllr}
\hline Parameter & Estimate & Standard error & $t$ Value \\
\hline cw 0 & -20.8 & 1.81 & -11.5 \\
cw 5 & -26.1 & 1.97 & -13.3 \\
cw 10 & -29.5 & 1.98 & -14.9 \\
cw 20 & -33.8 & 2.02 & -16.7 \\
cw 30 & -36.8 & 2.16 & -17.0 \\
$\rho$ & 0.24 & 0.0038 & 63.2 \\
\hline
\end{tabular}

Simple linear model for bending strength (MOR)

The calculated parameters for the regression can be seen in Table 7 .

The equations for the different percentage of compression wood read for MOR by the simple linear model are similar to Eq. 4. For example, Eq. 6 applies for $\mathrm{cw}=0$ :

$$
\mathrm{MOR}_{d h 0}=-20.8+0.24 \times \rho .
$$

As for the three E-modules, the fit for the maximal stress is also excellent, namely $R^{2}=0.82$ (the pattern is the same but, of course, the regression coefficients are totally different). Equally, the coefficient of determination $R^{2}$ is only marginally reduced, from 0.85 for the full model to 0.82 for the simple linear model.

\section{Conclusions}

In the radial direction, a clear tendency was found for selected wood properties: Density, MOE and bending MOR increased from pith to bark and with decreasing annual ring width. These properties highly influence the quality of wood products. Therefore, the superior properties close to the bark and in regions with a small width 
of growth rings are very important advantages of trunks with large diameters and of slow-grown timber as well (cf. Teischinger and Müller 2006).

Our evaluation of mechanical properties reveals that density combined with the proportion of compression wood is the most important parameter. All three elasticity moduli (static MOE, MOEs calculated from eigenfrequency and sound velocity) and bending strength can be very well predicted as a linear function of the density with a common gradient across the compression wood (cw) values but with different intercepts that decrease with increasing $\mathrm{cw}$. The other analysed variables (side of the tree, height in the tree, distance from the bark, annual ring width) have also a highly significant impact on the mechanical properties, however, they increase the correlation only marginally.

\section{References}

Arnold M (2004) Holzqualität und Verwendung von Sturmholz (Winddruckstauchungen). Schlussbericht. Lothar - Evaluations- und Grundlagenprojekte, Teilprogramm 3, Wald- und Holzwirtschaft, Projekt WN 24/00, BUWAL/Eidg. Forstdirektion, Bern

DIN 52186 (1978) Prüfung von Holz; Biegeversuch

Glos P, Pahler A (2006) Fichtenstarkholz - Problemsortiment oder Chance? Schweiz Z Forstwes 157:539-545

Görlacher R (1984) Ein neues Messverfahren zur Bestimmung des Elastizitätsmoduls von Holz. Holz Roh- Werkst 42:219-222

Kliger IR, Perstorper M, Johansson G, Pellicane PJ (1995) Quality of timber products from Norway spruce. Part 3. Influence of spatial position and growth characteristics on bending stiffness and strength. Wood Sci Technol 29:397-410

Knigge W, Schulz H (1966) Grundriss der Forstbenutzung. Parey, Hamburg und Berlin, p 584

Kollmann F (1951) Technologie des Holzes und der Holzwerkstoffe. Band 1. 2. Auflage. Springer, Berlin, p 1050

Kollmann F (1978) Schwankungen von Wachstum, Zuwachs und spezifischer Masse (Rohdichte und Raumdichte) bei Hölzern. Holz Roh- Werkst 36:111-119

Machado JS, Cruz HP (2005) Within stem variation of Maritime Pine timber mechanical properties. Holz Roh- Werkst 63:154-159

Mette HJ (1984) Holzkundliche Grundlagen der Forstnutzung. Dt. Landwirtschaftsverlag, Berlin, p 148

Niemz P (1993) Physik des Holzes und der Holzwerkstoffe. DRW-Verlag, Leinfelden-Echterdingen, p 243

Perstorper M, Pellicane PJ, Kliger IR, Johansson G (1995a) Quality of timber products from Norway spruce. Part 1. Optimization, key variables and experimental study. Wood Sci Technol 29:157-170

Perstorper M, Pellicane PJ, Kliger IR, Johansson G (1995b) Quality of timber products from Norway spruce. Part 2. Influence of spatial position and growth characteristics on warp. Wood Sci Technol 29:339-352

Perstorper M, Johansson M, Kliger R, Johansson G (2001) Distortion of Norway spruce timber. Holz Roh- Werkst 59:94-103

Reiter JMG (2005) Fichtenstarkholz (Picea abies (L.) Karst.) - Untersuchungen zur Rundholzqualität und deren Einfluss auf die Schnittholzqualität. Dissertation, TU München

Sonderegger W, Niemz P (2004) The influence of compression failure on the bending, impact bending and tensile strength of spruce wood and the evaluation of non-destructive methods for early detection. Holz Roh- Werkst 62:335-342

Teischinger A, Müller U (2006) Holzeigenschaften von Nadelstarkholz und sein technologisches Potenzial. Schweiz Z Forstwes 157:561-564

Timell TE (1986) Compression wood in gymnosperms, vol 1. Springer, Berlin, p 706

Trendelenburg R (1937) Über Stammwuchsuntersuchungen und ihre Auswertung in der Holzforschung. Holz Roh- Werkst 1:3-13 
Volkert E (1941) Untersuchungen über Grösse und Verteilung des Raumgewichts in Nadelholzstämmen. Schriftenreihe der Hermann-Göring-Akademie der Deutschen Forstwissenschaft, Band 2. J.D. Sauerländer's Verlag, Frankfurt am Main, p 133

Vorreiter L (1937) Bau und Festigkeitseigenschaften des Holzes der Glatzer Schneebergsfichte Thar. Forstl. Jahrbuch 88:65-126, 235-285, 351-385

Vorreiter L (1954) Stammform und Holzeigenschaften der Bayernwald-Fichte. Holz Roh- Werkst $12(2): 47-54$

Walker JCF (2006): Primary wood processing: principles and practice, 2nd edn. Springer, Dordrecht, p 596

Zobel BJ, Van Buijtenen JP (1989) Wood variation: its causes and control. Springer, Berlin, p 363 